Supporting Information for

\title{
Self-healing, Self-adhesive Strain Sensors Made with Carbon Nanotubes/Polysiloxanes Based on Unsaturated Carboxyl-Amine Ionic Interactions
}

\author{
Dongdong Mai ${ }^{1,2, *}$, Jiaheng Mo ${ }^{1}$, Shijie Shan ${ }^{1}$, Yaling Lin $^{3}$, Anqiang Zhang ${ }^{1, * *}$ \\ 1. School of Materials Science and Engineering, South China University of Technology, 381 Wushan Rd., \\ Guangzhou 510641, Guangdong, China \\ 2. School of Materials Science and Engineering, Guangdong University of Petrochemical Technology, \\ Maoming 525000, China \\ 3. College of Materials and Energy, South China Agricultural University, 483 Wushan Rd., Guangzhou \\ 510642, Guangdong, China \\ * Corresponding author: Dongdong Mai. Email address: ddmai@gdupt.edu.cn \\ ** Corresponding author: Prof. Anqiang Zhang. Email address: aqzhang@scut.edu.cn
}

Part S1. Synthesis of aminopropyl-pendent polysiloxanes (APPS) and unsaturated carboxyl polysiloxanes (UCPS)

Part S2. Characterization of UCA polysiloxanes substrate

Part S3. Assembly of strain sensor

Part S4. The comparison of gauge factors of strain sensors reported in the literature and this work

Part S5. Tape test for stability of CNTs/polysiloxanes strain sensor

Part S6. Strain sensor for monitoring swallowing and coughing 


\section{Part S1. Synthesis of aminopropyl-pendent polysiloxanes (APPS) and unsaturated carboxyl polysiloxanes (UCPS)}

Aminopropyl-pendent polysiloxanes (APPS) were synthesized in previous work and a brief procedure is as follows. A mixture of APDES (191 g, $1.0 \mathrm{~mol})$ and water (39.6 g, 2.2 mol) were blended at room temperature for $4 \mathrm{~h}$ under stirring. After the reaction, the mixture was concentrated under reduced pressure to remove volatiles, and polyaminopropylmethylsilane (PAMS) was obtained as colorless oil (Yield: 95\%).

$\mathrm{D}_{4}$, PAMS, AMM and $\mathrm{Me}_{4} \mathrm{NOH} \cdot 5 \mathrm{H}_{2} \mathrm{O}$ (catalyst, $0.2 \%$ ) were heated and maintained at $90{ }^{\circ} \mathrm{C}$ for $10 \mathrm{~h}$ under nitrogen atmosphere. After the reaction, the mixture was heated to $150{ }^{\circ} \mathrm{C}$ for $1 \mathrm{~h}$ to decompose the catalyst, and then concentrated under reduced pressure to remove volatiles. The obtained aminopropyl-pendent polysiloxanes were named APPS- $x$ ( $x=$ 5 and 10 for different aminopropyl groups grafting degrees, as shown in Table S1). Its synthetic route is depicted in Scheme S1.

FT-IR (ATR, $\left.\mathrm{cm}^{-1}\right): 2966,2906,1614,1415,1262,1096,1026,868,805 .{ }^{1} \mathrm{H}-\mathrm{NMR}$ $\left(\mathrm{CDCl}_{3}, 600 \mathrm{MHz}, \mathrm{ppm}\right): 0-0.18$ (m, Si-CH 3$), 0.46-0.55$ (t, $\left.-\mathrm{CH}_{2}-\mathrm{CH}_{2}-\mathrm{CH}_{2}-\mathrm{NH}_{2}\right), 1.40-1.50$ (m, $\left.-\mathrm{CH}_{2}-\mathrm{CH}_{2}-\mathrm{CH}_{2}-\mathrm{NH}_{2}\right), 2.63-2.68\left(\mathrm{~m},-\mathrm{CH}_{2}-\mathrm{NH}_{2}\right)$.

(a)

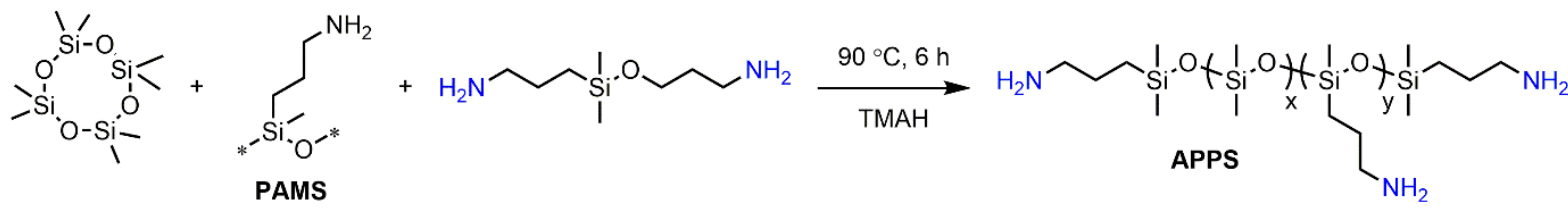<smiles>O=C1C=CC(=O)C(=O)O1</smiles><smiles>[X]C(C)(O[Si](C)(C)O[Si](C)(C)CCCNC(=O)/C=C\C(=O)O)[Si](C)(C)O[Si](C)(C)O[Si](C)(C)CCCNC(=O)/C=C\C(=O)O</smiles>

Scheme S1. Synthesis route of aminopropyl-pendent polysiloxanes (APPS) and unsaturated carboxyl polysiloxanes (UCPS). 
APPS-10 (20 g) and maleic anhydride (3.74 g, $25.4 \mathrm{mmol})$ were dissolved and stirred under $80{ }^{\circ} \mathrm{C}$ for $10 \mathrm{~min}$, and UCPS was obtained as a light-yellow viscous oil. Yield: $98 \%$. Its synthetic route is also depicted in Scheme S1.

FT-IR (ATR, cm ${ }^{-1}$ ): 3270, 2966, 2906, 1714, 1640, 1560, 1445, 1409, 1262, 1096, 1026, 868, 805. ${ }^{1} \mathrm{H}-\mathrm{NMR} \quad\left(\mathrm{CDCl}_{3}, 600 \mathrm{MHz}, \mathrm{ppm}\right): 0-0.18 \quad\left(\mathrm{~m}, \mathrm{Si}-\mathrm{CH}_{3}\right), 0.50-0.58$ (t, $-\mathrm{CH}_{2}-\mathrm{CH}_{2}-\mathrm{CH}_{2}-\mathrm{NH}-$ ), 1.57-1.68 (m, $-\mathrm{CH}_{2}-\mathrm{CH}_{2}-\mathrm{NH}-$ ), 3.29-3.38 (m, - $\mathrm{CH}_{2}-\mathrm{NH}-$ ), 6.26-6.55 (d, $-\mathrm{C} H=\mathrm{C} H-)$.

Table S1. Formulations of APPS- $x$.

\begin{tabular}{llllll}
\hline Sample & $\mathrm{D}_{4}(\mathrm{~g})$ & PAMS $(\mathrm{g})$ & $\mathrm{AMM}(\mathrm{g})$ & $\mathrm{Me}_{4} \mathrm{NOH} \cdot 5 \mathrm{H}_{2} \mathrm{O}(\mathrm{g})$ & Amine Values $(\mathrm{mmol} / \mathrm{g})^{a}$ \\
\hline APPS-5 & 140.6 & 11.7 & 0.76 & 0.30 & 0.624 \\
APPS-10 & 66.6 & 11.7 & 1.95 & 0.16 & 1.27 \\
\hline
\end{tabular}

a. Amine values were determined by acid-base titration. 
(a)
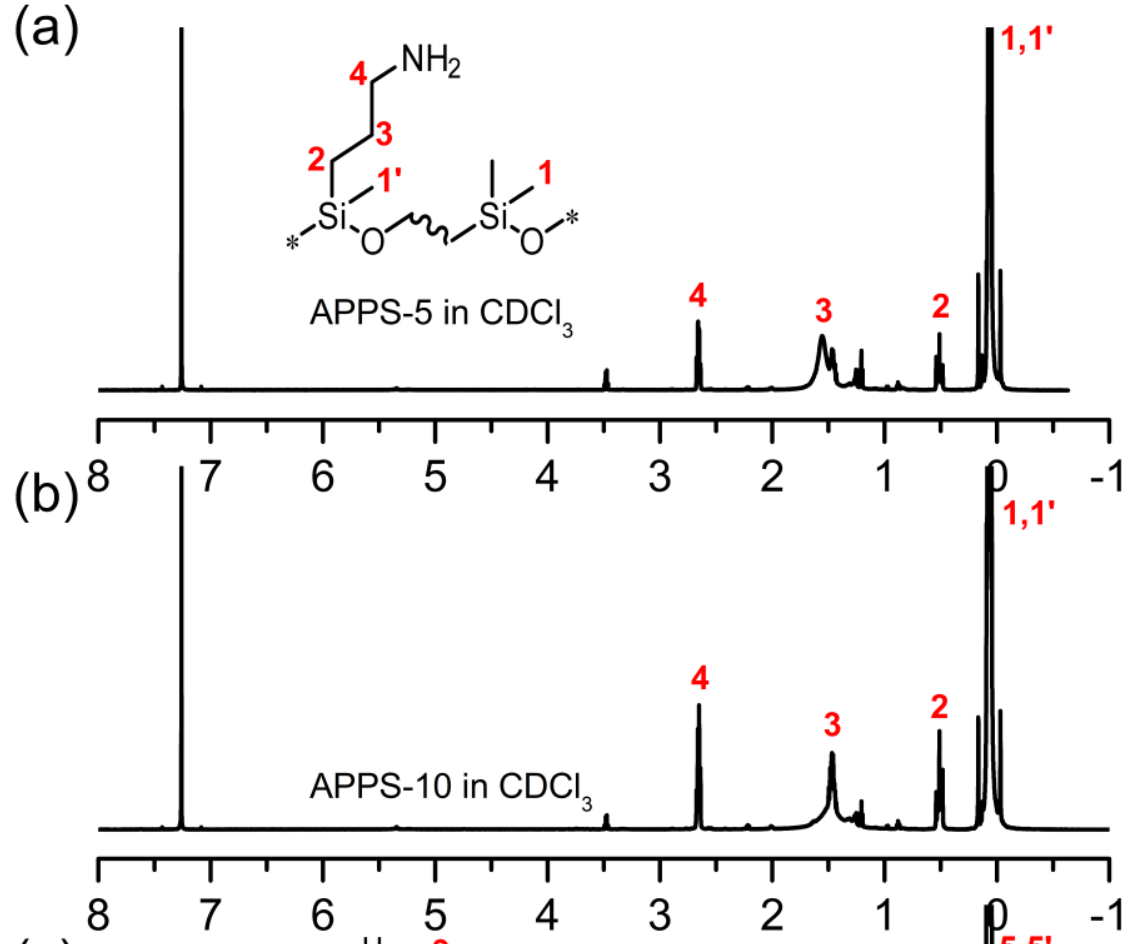

(c)

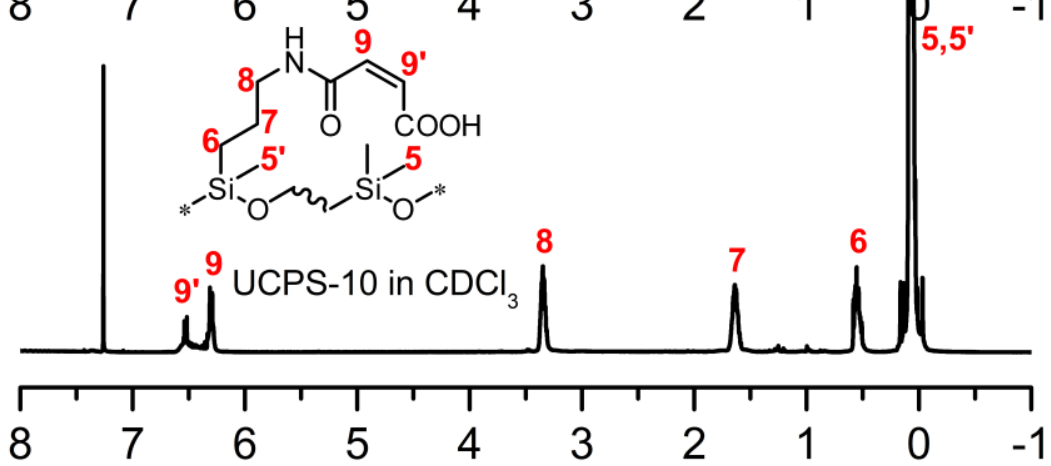

(d)

Chemical shift (ppm)

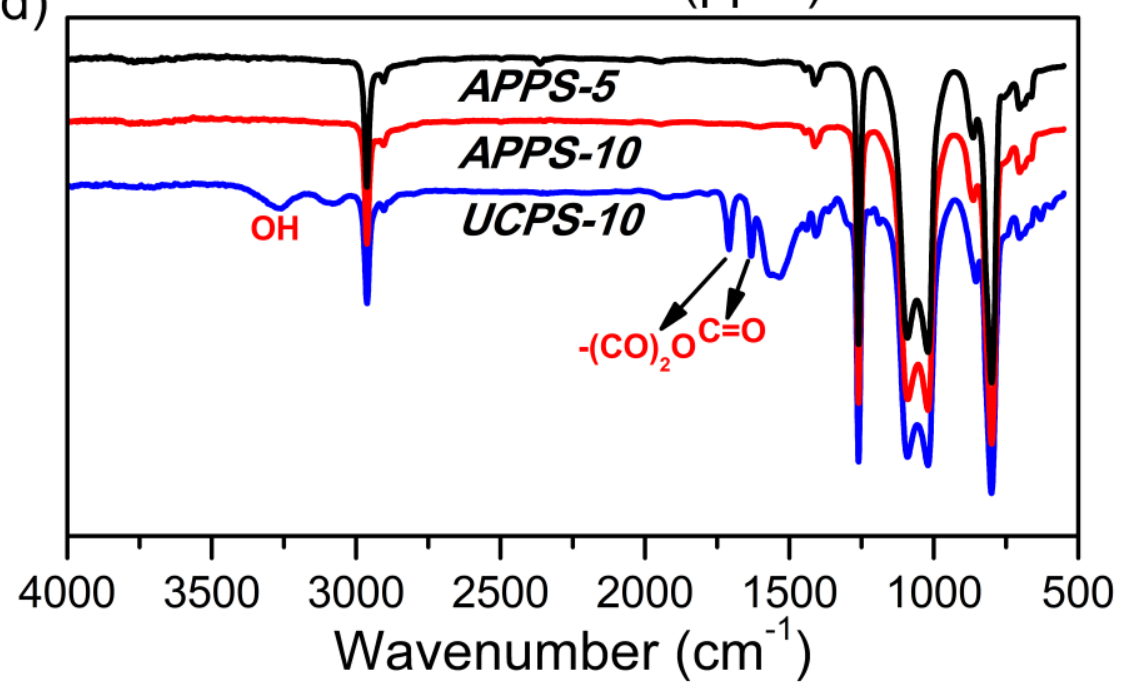

Figure S1. ${ }^{1} \mathrm{H}$ NMR spectra of APPS-5 (a), APPS-10 (b) and UCPS-10 (c); FTIR spectra of APPS- $x$ and UCPS-10 (d). 
Table S2. Molecular weights of APPS- $x$ and UCPS-10 from the GPC tests.

\begin{tabular}{lll}
\hline Sample & $M_{\mathrm{n}}(\mathrm{kDa})$ & $Ð\left(M_{\mathrm{n}} / M_{\mathrm{w}}\right)$ \\
\hline APPS-5 & 20.2 & 1.85 \\
APPS-10 & 10.3 & 1.54 \\
UCPS-10 & 10.1 & 1.72 \\
\hline
\end{tabular}

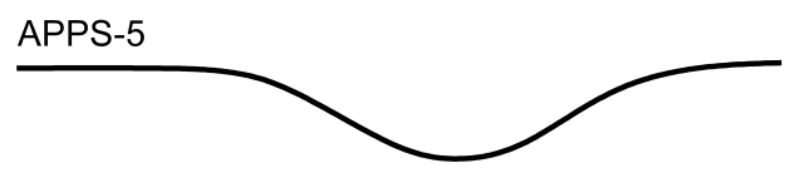

APPS-10
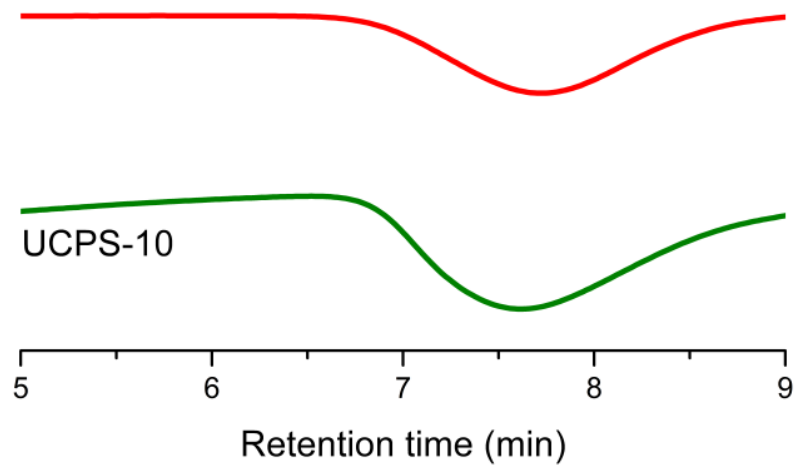

Figure S2. GPC curves of APPS-5, APPS-10, and UCPS-10. 


\section{Part S2. Characterization of UCA polysiloxanes substrate}
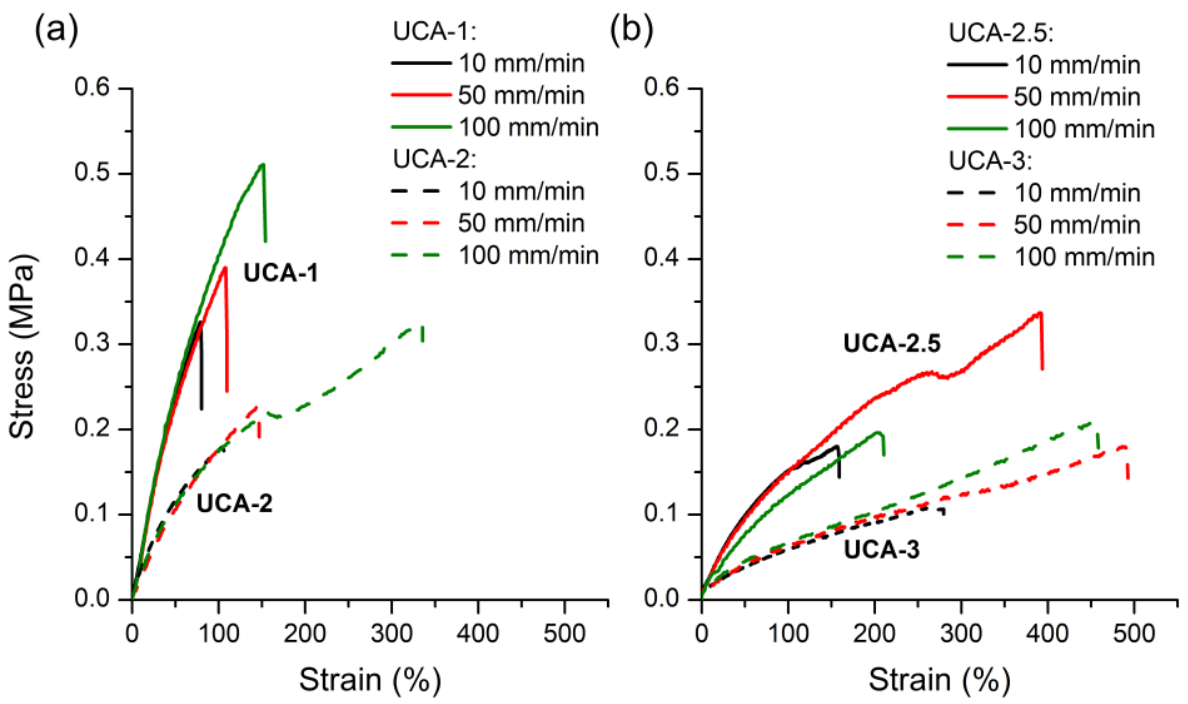

Figure S3. Tensile strain-stress curves of UCA- $x$ stretched at different stretching speeds.

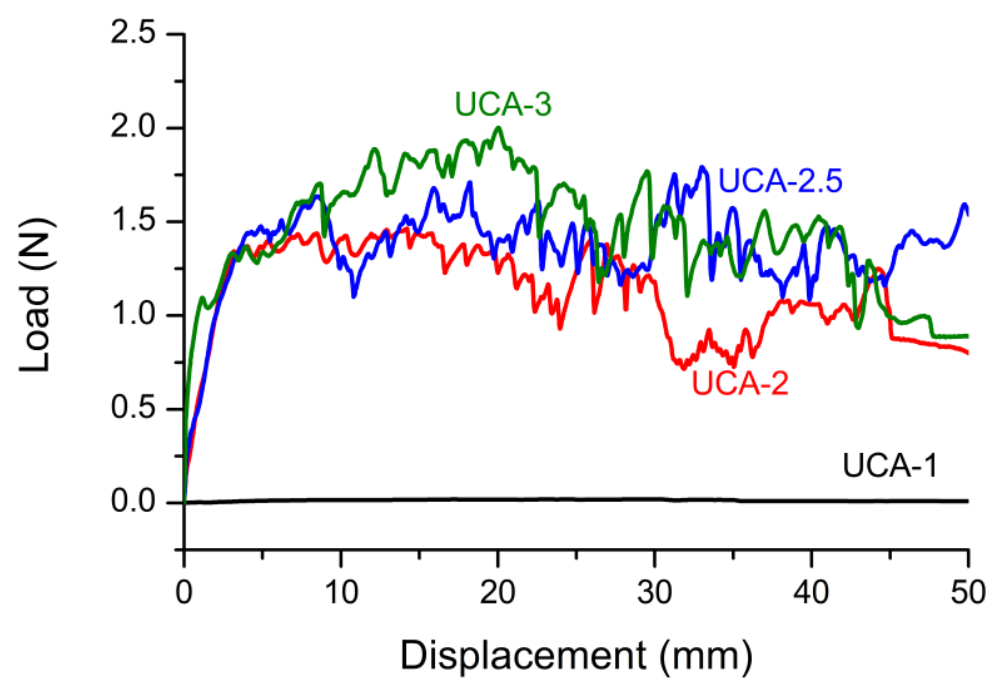

Figure S4. Peeling strength curves of the UCA- $x$ on a clean glass plate.

$90^{\circ}$ peeling tests were carried out on a KJ-2091 tensile testing machine which was used in tensile testing. All samples were cut into rectangular size $(10 \times 120 \times 2 \mathrm{~mm})$ and attached to the tested plate, a clean smooth glass with a tin foil. Samples were adhered to the glass plate without pressure for $3 \mathrm{~h}$ before tests. The peeling rate was $50 \mathrm{~mm} / \mathrm{min}$ at $90^{\circ}$. Each group was repeated for three times. 


\section{Part S3. Assembly of strain sensor}
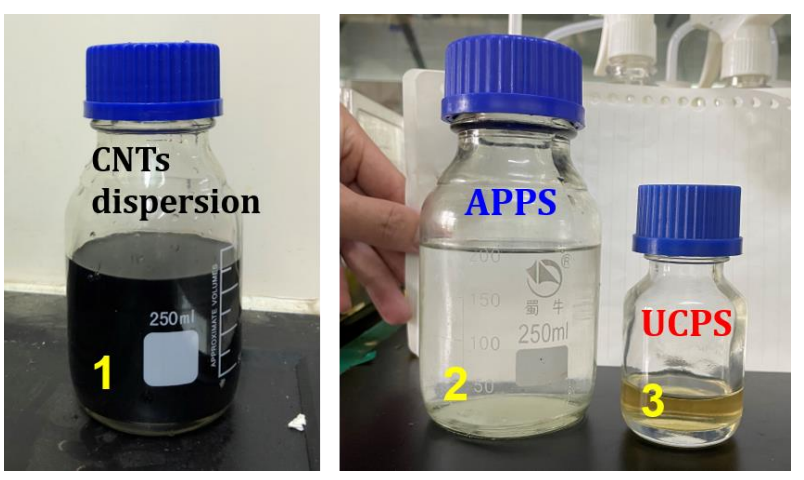

Figure S5. 1: CNTs dispersion in ethanol with a concentration of $0.02 \mathrm{mg} / \mathrm{mL}$. 2: Aminopropyl-pendent polysiloxanes (APPS). 3: Unsaturated carboxyl polysiloxanes (UCPS).

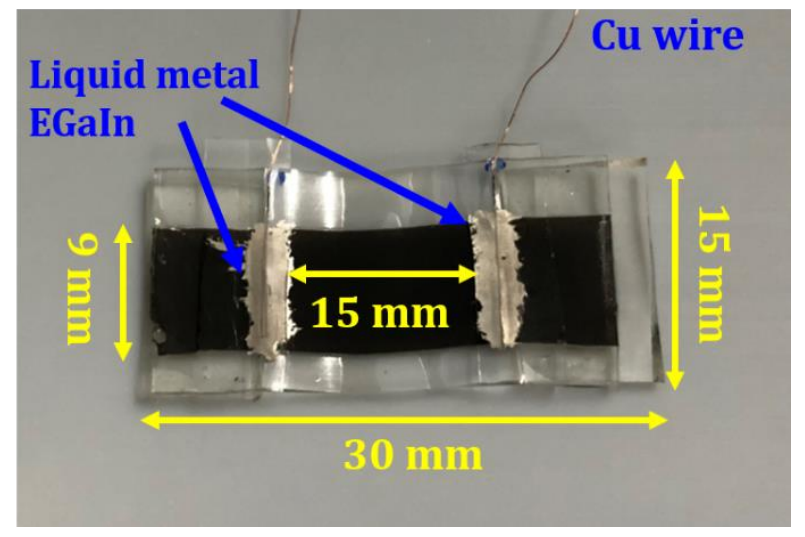

Figure S6. Schematic illustration of the strain sensor structures. 
(a)

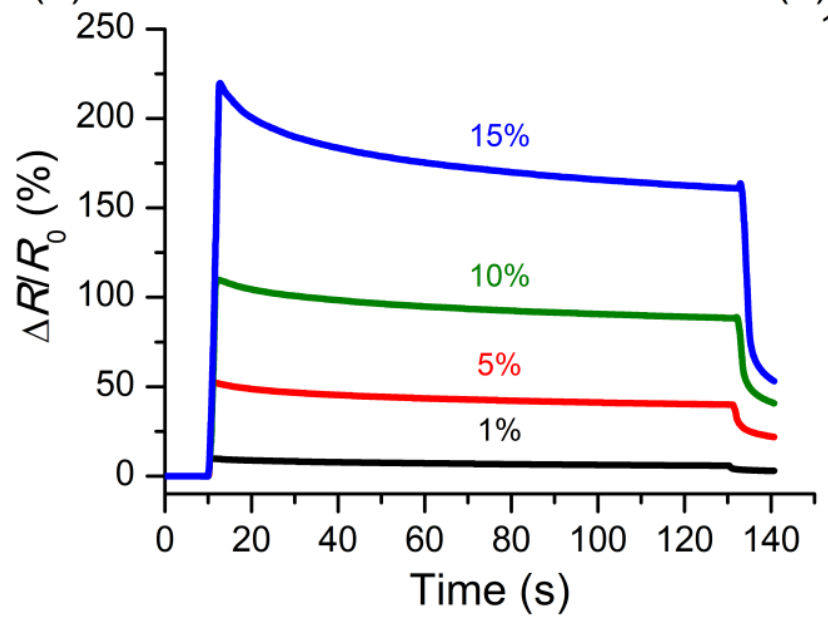

(b)

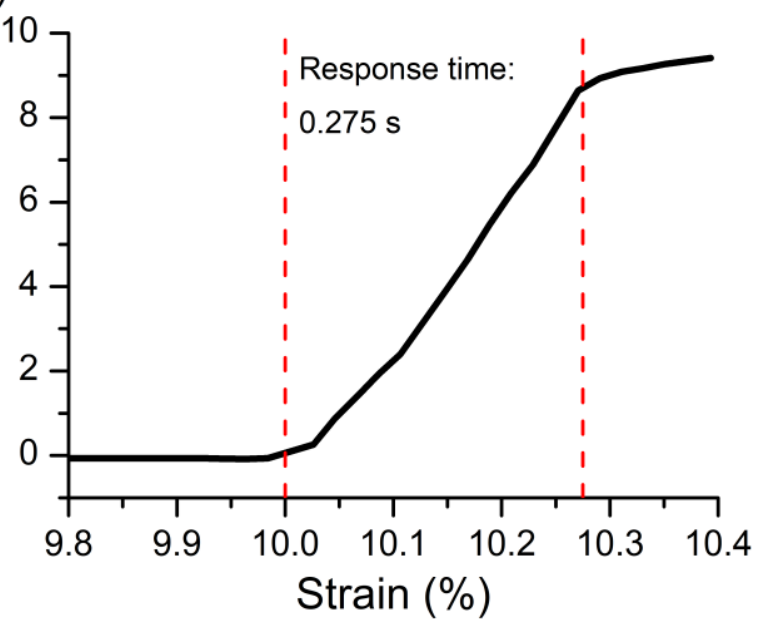

Figure S7. (a) Resistance changes of CNTs/polysiloxanes strain sensor UCA-2.5@CNTs-20 as function of time subjected to step strain 1\%,5\%,10\%, and 15\%. (b) Electrical response of UCA-2.5@CNTs-20 subjected to instant strain $1 \%$, and the response time is $0.275 \mathrm{~s}$.

Table S3. Relative resistance $\left(\Delta R / R_{0}\right)$ and resistance $(R)$ of CNTs/polysiloxanes strain sensor.

\begin{tabular}{clllll}
\hline Sample & $R_{0}(\mathrm{k} \Omega)$ & $R$ at $30 \%$ & $\Delta R / R_{0}(\%)$ at & $R$ at $55 \%$ strain & $\Delta R / R_{0}(\%)$ at \\
& & strain $(\mathrm{k} \Omega)$ & $30 \%$ strain & $(\mathrm{k} \Omega)$ & $55 \%$ strain \\
\hline UCA-2.5@CNTs-10 & 351 & 685 & 95 & 882 & 151 \\
UCA-2.5@CNTs-15 & 86 & 261 & 203 & 525 & 510 \\
UCA-2.5@CNTs-20 & 40 & 371 & 816 & 797 & 1869 \\
\hline
\end{tabular}


Part S4. The comparison of gauge factors of strain sensors reported in the literature and this work

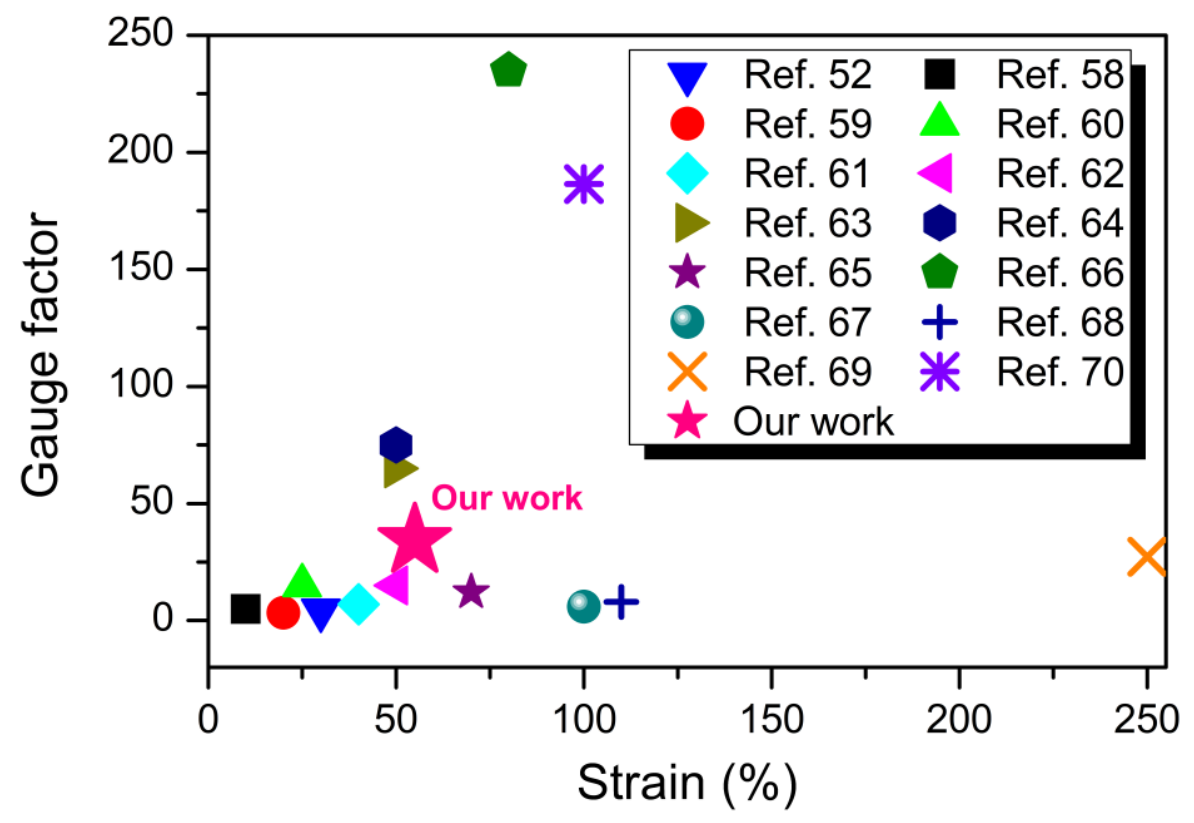

Figure S8 Comparisons of gauge factors of strain sensors reported in the literature. 


\section{Part S5. Tape test for stability of CNTs/polysiloxanes strain sensor}
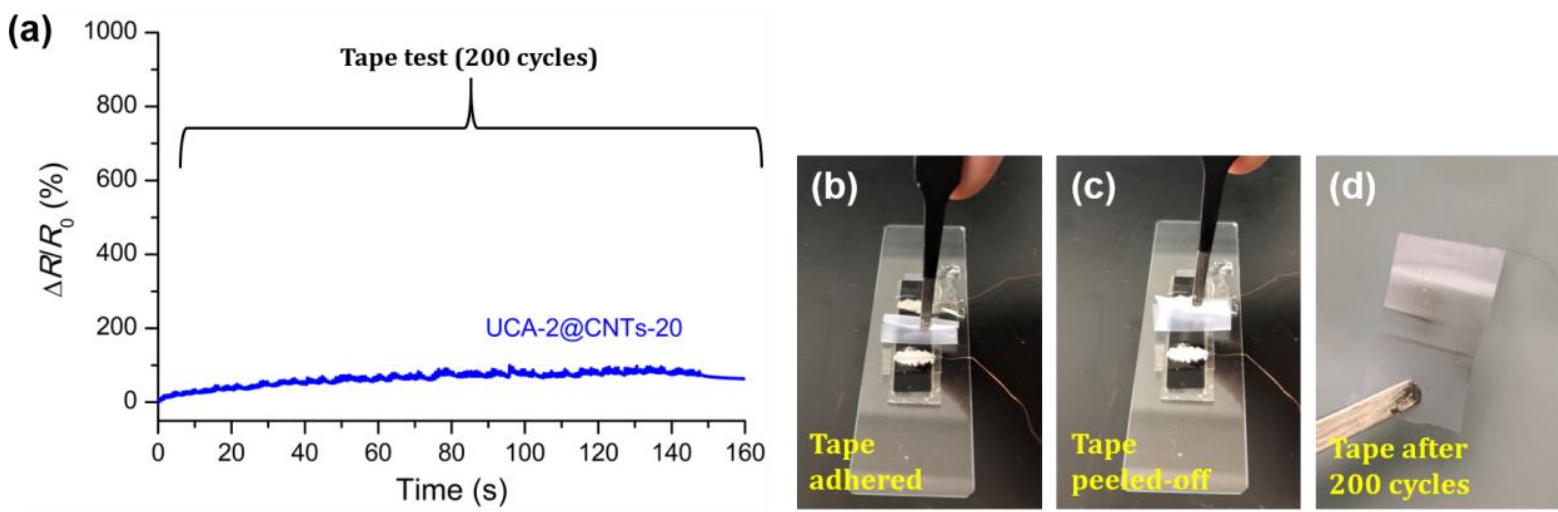

Figure S9. Tape test of conductive CNTs/polysiloxanes composites. (a) Plot of resistance changes of CNTs/polysiloxanes strain sensor UCA-2@CNTs-20. Photographs for peeling off the 3M tape from the composite film (b) and the peeled-off tape without any CNTs left. The tape test was repeated up to 200 cycles. 


\section{Part S6. Strain sensor for monitoring swallowing and coughing}

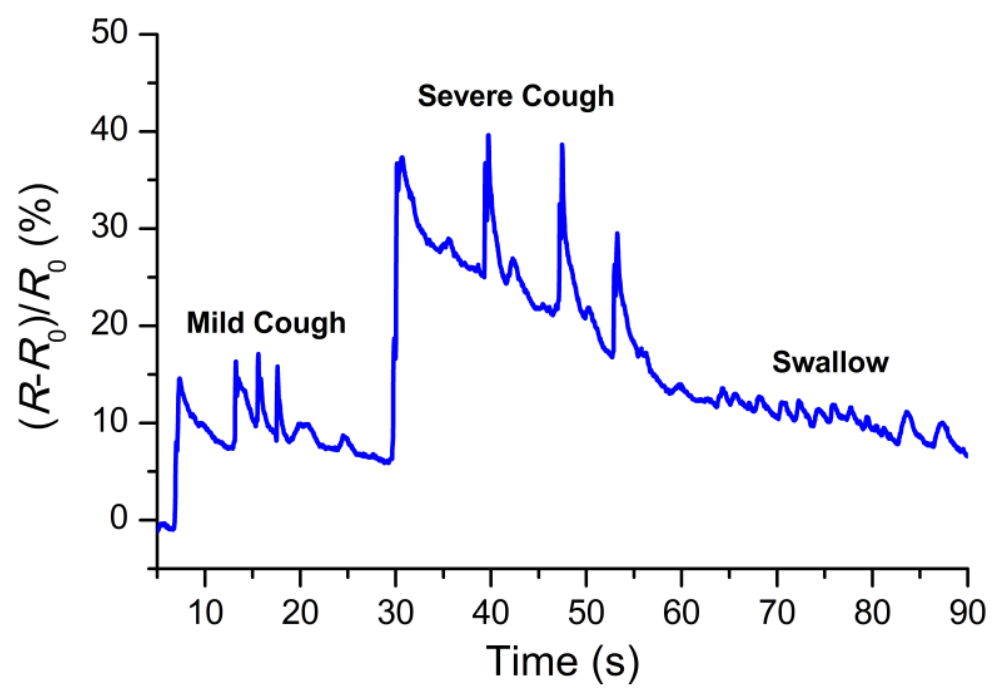

Figure S10. Monitoring of coughing and swallowing in real time. CNTs/polysiloxanes strain sensor attached on the prominentia laryngea of a male tester. 